\title{
Study on Digital Manufacturing Alliance System He Miao
}

\author{
(NanChang Institute of Science \& Technology, Nanchang,330108; Jiangxi Engineering Laboratory \\ of Digital Manufacturing for Automobile Parts)
}

Keywords: Digital Manufacturing Technology; Digital Manufacturing; Alliance system

\begin{abstract}
Digital design and manufacturing are playing an increasingly important role in many related fields such as advanced manufacturing technology, medical rehabilitation equipment and biological engineering. From the advent of CNC machine tools in the 1950s, digital manufacturing technology has undergone rapid development through the development process of cell manufacturing technology, integrated manufacturing technology, and networked manufacturing technology. On the basis of reading a large number of relevant documents, this article introduces the digital technology, summarizes the research status of digital manufacturing technologies at home and abroad, discusses that digital manufacturing technology is the core of advanced manufacturing technology, and also demonstrates several core technologies of digital manufacturing technology. At last, this paper summarizes the profound changes and development of digital manufacturing.
\end{abstract}

\section{Introduction}

Before the advent of computer technology, drawing design and manual processing are adopted for designing and processing mechanical products. This traditional product design and manufacturing method made the product totally dependent on product designers and their professionals in terms of quality and the product yield is totally depend on how familiar they are with the products and how quick they can produce. With the continuous development of the industrial society, people have put forward higher requirements on the quality of mechanical products, and at the same time, the demand on quantity has also increased. In order to meet the society's demand for quality and quantity of mechanical products, and to further reduce the production costs of mechanical products, people are striving to find a new way of designing and processing mechanical products. With the emergence of computer technology and its development in 1940s and 1950s, especially the emergence of computer graphics, people have seen the dawn of changes in the design and production of traditional mechanical products. As a result, digital design and production methods came into being. People gradually hand over the design and processing tasks of mechanical products to computers. On the one hand, the design cycle of mechanical products is greatly shortened, and on the other hand, the quantity and quality are separated from the design and processing personnel, which greatly enhanced the quality, reduced the production cost, making the products for massive manufacturing purpose. However, there is no doubt about the reform of digital manufacturing. In addition to technical reforms, there should be collective reforms in the digital manufacturing industry.

\section{Digital Manufacturing Technology and the Concept Of Digital Manufacturing}

Digital manufacturing technology means that under the support of virtual reality, computer networks, rapid prototyping, databases, and multimedia, it rapidly collects resource information, analyzes plans and restructures product information, processing information and resource information according to the needs of customers so as to realize products simulation and manufacturing quickly and meet the requirement of customers.

Digital manufacturing is a process to make digital description of the manufacturing procedure and complete manufacturing in the digital space. Digital manufacturing is the result of the continuous integration, development, and application of computer digital technology, network information technology, and manufacturing technology. It is also a necessity for continuous digitization of manufacturing companies, manufacturing systems, and production systems. 
Computer simulation technology is considered as a comprehensive technology to carry out an experiment on the actual or envisaged systems based on similar principles, information technology, system technology, and professional technologies in corresponding fields and with the assistance of computer and various physical effect devices. The technology describes the process or the system by establishing a process or a model of a system, and then uses a series of purposeful, conditional computer simulations to characterize the system so as to get the quantitative indicators, which can provide the quantitative analysis results of this process or system to decision makers and serve as the theoretical basis for decision making.

\section{Digital Manufacturing Auxiliary Tools}

With the development of computer and network technology, digital manufacturing technologies based on multimedia computer systems and communication networks have made it possible for parallel manufacturing, distributed operation, virtual collaboration, and remote operation and monitoring of modern manufacturing systems. The digital manufacturing technology aids and functions are as follows:

(1) Use integration tehcnology based on web AD/CAE/CAPP/CAM/PDM (C4P) to achieve full digital product design and manufacturing. In the CAD/CAM application process, using product data management PDM technology to achieve parallel engineering can greatly improve the efficiency and quality of product development. As shown in Figure 1:

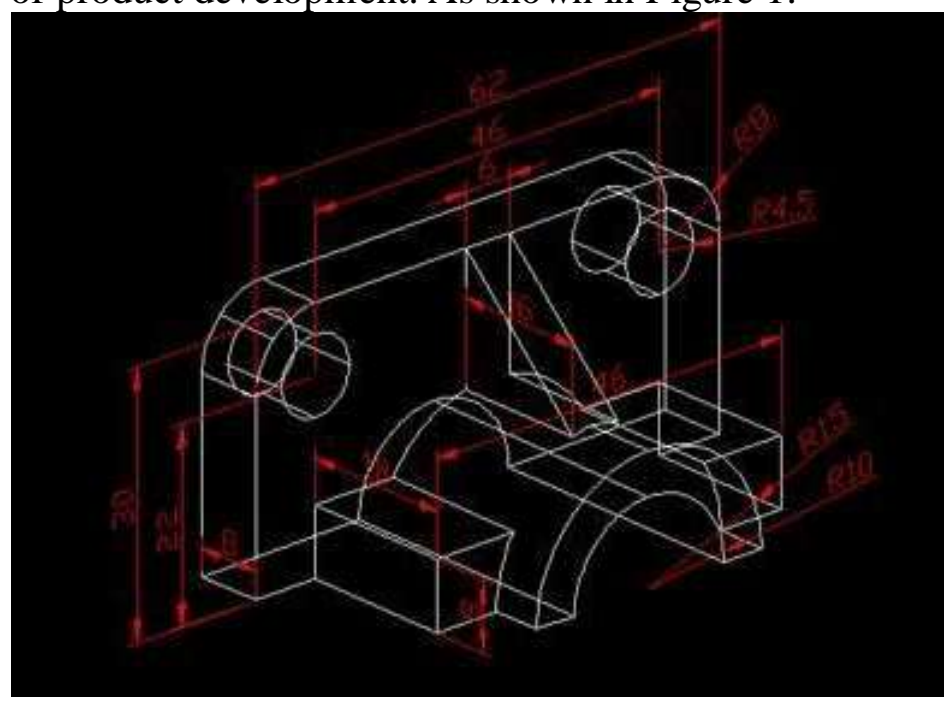

Figure $1 \mathrm{CAD}$ drawing effects

(2) The integration of CAD / CAE / CAPP / CAM / PDM technology and enterprise resource planning, supply chain management, customer relationship management form the overall structure of manufacturing enterprise information. CAD/CAE/CAPP/CAM/PDM technology is mainly used to realize the digitization of product design, process, manufacturing process and management; ERP is to realize the management of production, supply, sales, people, finance, and material of enterprises. Supply chain management SCM is used to achieve the logistics management between the company's internal and upstream companies; customer relationship management CRM can help companies establish, mine and improve the relationship with customers

(3) Virtual design, virtual manufacturing, virtual enterprise, dynamic enterprise alliance, agile manufacturing, network manufacturing, and manufacturing globalization will become important directions for digital design and manufacturing technology development. Virtual design and virtual manufacturing technology will help tp create virtual environments, virtual design, manufacturing processes, virtual products, and virtual companies in the premise of computer-supported simulation technology, which can thereby greatly shorten the product development cycle and improve the success rate of product design and development. 


\section{Digital Manufacturing Alliance System Research}

Deutscher Werkbund is German's first design organization, founded in 1907, and is the cornerstone of German modernist design. It laid the foundation for the rise and development of European modernism design movement in the 1920s in both theory and practice.

Its purpose is to improve the German design level through the combination of art, industry and craftsmanship, and to design superior products. The Alliance believes that the purpose of design is human beings, not objects. Industrial designers are public servants of the society, not artists who are self-representative. In the premise of affirming mechanized production, mass production and product standardization are the basic requirements for design. The GMC Quality Manufacturers Alliance is a high-quality manufacturer group formed by the Global Market Group and consists manufacturers that meet the eight standards of the Global Manufacturer Certificate (GMC).

The GMC quality manufacturer auditing standards include whether it is a true manufacturer, the ability to produce high-quality products, the scale of the company, professional foreign trade team and experience, product research and development capabilities, social and environmental responsibility, reputation/goodwill, and OEM/ODM experience. Only high-quality manufacturers that meet the GMC's eight standards can join the GMC High-Quality Manufacturers Alliance to jointly enjoy this group brand representing high-quality "Made in China". The exposure of Chinese manufacturers has reduced the cost and time of international professional buyers searching for quality Chinese manufacturers and ensured the quality of international trade.

Both alliances play their own function. However, the alliance of these manufacturing alliances will make products better go out and have more quality guarantees. Therefore, making alliances is extremely important and resource sharing has become the biggest advantage of the alliance system.

\section{Conclusion}

Compared with developed countries, China's manufacturing industry is not strong in innovation, and high-tech is still in a catch-up state. Many key core technologies have not yet been mastered, and the overall competitiveness of manufacturing industries is weak. Generally, it is in the low-end of international division of labor and the industrial chain. At present, the proportion of high-tech industries in China accounts for about one-third of the United States. The structure of China's manufacturing industry needs to be optimized, and the proportion of digital manufacturing in the manufacturing industry needs to be improved. Manufacturing alliances is a guarantee for the continued development of China's manufacturing industry, which can enable it a foothold in China and the world.

\section{Acknowledgement}

Project funding: Project at Nanchang institute of science and technology (No.SZZX-17-27)

\section{References}

[1] Zhang J M. Research on multi-agent based collaborative purchasing architecture for manufacturing alliance[J]. Journal of Wuhan University of Technology, 2009, 31(10):137-139.

[2] Liu F L. Research on Logistics System of Manufacturing Enterprise Based on Regional Dynamic Alliance[J]. Sci-Tech Information Development \& Economy, 2007.

[3] Cha V D. Powerplay: Origins of the U.S. Alliance System in Asia[J]. International Security, 2009, 34(3):158-196.

[4] Bi K X, Meng L. Research on the mode and evolution of industry-university-research strategic alliance in manufacturing green innovation system[J]. 2013:569-578.

[5] Zhang S J, Yang C L. Research on Quality Evaluation System of Dynamic Alliance Based on Life-Cycle[J]. Advanced Materials Research, 2010, 97-101:4355-4358.

[6] Beddie F, Creaser M, Hargreaves J, et al. Readiness to meet demand for skills: a study of five growth industries[J]. Ncver, 2014. 
[7] Lee K, Mathews J. Science, technology and innovation for sustainable development[J]. Cdp Background Papers, 2013.

[8] Hirose K, Babasaki T. Smart Power Supply Systems for Mission Critical Facilities[J]. Ieice Trans Commun, 2012, 95(3):755-772.

[9] Chopra A, Corriveau P, Leafloor R, et al. Subjective evaluation of the digital HDTV grand Alliance system[J]. Canadian Journal of Electrical \& Computer Engineering, 2015, 23(1-2):11-16.

[10] Alvarez, Andres. Effects of multiwall carbon nanotubes on the mechanical properties of carbon-reinforced cyanate ester composites[J]. 2014.

[11] Naningrum A. Standardization Metadata Schema for Securing Interoperability[J]. 2012.

[12] Zar D L. Wineman Technology Selected to Showcase INERTIA ${ }^{\text {TM }}$ Software Platform at NIWeek 2013[J]. Pr Newswire. 